sparkle in the brilliant sunshine which penetrates the trees. At the bottom of the Devil's Cataract the great pool is always kept in a very turbulent state by the ever-falling torrent, creating waves at least two feet high on the far side of the pool, while the spray rises far above the precipitous sides and produces brilliant rainbows by day or by night at full moon. The wedge-shaped crevice cutting into Cataract Island gives clear evidence of earthquake activity and could not have been caused by erosion of the hard basalt rock. By descending hand over hand by means of a rope attached to a tree on the crest of the Falls on the Eastern Cataract, Mr. Clarke and his assistant got to the bottom of the abyss.

They observed that at the base of the Falls chasm the strata are vertical and run parallel to the Falls, yet the $300 \mathrm{ft}$. of basalt comprising the perpendicular face of the Falls appears to be in five distinct layers in the horizontal plane, each layer boing a shade different in colour. They swam across the pool beyond the base of the Eastern Cataract after convincing themselves that no crocodiles were present. They explored the entire base of the Falls for the first time and state definitely that no traces of animal remains were seen.

With the help of the chief surveyor, Mr. Younger, twelve careful readings of the height of the Falls wero taken. The maximum height was found to bo $355 \mathrm{ft}$., and this spot is at a place on the west side of the "Arm Chair". Devil's Cataract has a drop of $200 \mathrm{ft}$., while the Eastern Cataract is $282 \mathrm{ft}$. high.

\title{
ELECTRICALLY MANUFACTURED STEELS
}

\begin{abstract}
A
PAPER on elcctrically manufactured steels by

H. 13. Sieveking, of the Central Electricity Board, originally allocated for reading before the Institution of Electrical Engineers on November 23, has been cireulated owing to the decision not to hold meetings for the time being. Ho first gives a description of the two principal types of electric furnaces used; the main products are next discussed from a metallurgical point of view and the advantages and disadvantages of the two types of furnaces for meeting specific requirements are reviewed.
\end{abstract}

For the manufacture of steel two types of furnace have been developed-the arc and the high-frequency induction types. The low-frequency type is rarely used nowadays. Are furnaces aro used for melting or for keeping molten metal hot. Generally they are of the vertical 3-phase 3-electrode type. The furnace comprises a refractory hearth which may be of 'basic' (for example, magnesite, MgO) or 'acid' (for example, silica $\mathrm{SiO}_{2}$ ) material as required and in which the charge is placed. The necessary heat is obtained by electric ares formed between the chargo and the electrodes which project through the roof in triangular formation. In general, an acid lining is cheaper but this typo of lining is 'dead', that is, it does not allow of impurities being removed from the bath. The more expensive basic lining, on the other hand, is suitable for refining. The position of the electrodes is adjusted either by hand or automatically. Hand adjustment is simple but is apt to givo rise to violent fluctuations of power. Some form of automatic control, consisting of an electric motor, or a hydraulic servo motor on each electrode, is to be preferred. A special transformer is used with special tappings which allow of a voltage variation from 60 to 250 during sorvice. The largest size in practice will usually take a charge of about 30 tons. There is one in use in America which has six arcs and will take a charge of 100 tons.

There exist to-day a very large number of alloy steels, some of which present manufacturing difficulties which can only be overcome in an electric furnace. Let us first consider the high-frequency furnace. It has very thin walls but it is possible to get through about fifty charges without relining. 'This corresponds to about one reek's working. 'The advantages of this type of furnace are: the absence of oxidizing at mosphere, no carbon pickup, suitability for intermittent operation and high temperatures are obtainable. The disadvantages are its high capital cost and limited capacity. It is known that an arc furnace load is such that with a good operating power factor the short-circuit current swings to be taken on the mains will not exceed twice full load. The swings usually occur in the first half of the melting period. In Great IBritain until 1934 the proportion of electric steel was nearly constant, with two well-marked exceptions in 1918 and 1926the last year of the War and the year of the General Strike respectively. Since 1934, which corresponds to a period first of trade depression and then of rearmament, there has been a steady increaso in the proportion.

In the United States the electric steol follows very closely the total output of steol. The United States, Germany and Great Britain stand respectively first, second and third in regard to total output, but sixth, eighth and ninth in respect of proportion of electric steel produced, being above only Luxembourg and Belgium. The countries producing the greatest proportion of steel electrically aro Italy and Swedencountries rich in water power and poor in coal, and only standing seventh and eleventh in regard to total output. The world output of electric steel is about 3 per cent of the total, but if Italy and Sweden are omitted the proportion is only 2 per cent. From the tables given in the paper it is evident that in Great Britain the term electric steel must be confined at present to steels which have a high selling price. The weight of finished steel used to-day is far higher than that required in theory as engineers use a high factor of safety: With ordinary steel the material structure is not uniform and therefore the strength of the weakest point must be guessed and the steel dimensioned accordingly. An electric steel, on the other hand, has a very uniform structure and it would therefore seem possible to reduce the factor of safety at least by an amount sufficient to make the total cost of the steel requirements the same whether the steel is manufactured electrically or by one of the other methods. It is undoubtedly along these lines that some countries are working at the present time in order to reduce their internal steel consumption to a minimum. 